\title{
Using Computerized Corpus Analysis To Investigate The Textlinguistic Discourse Moves Of a Genre
}

\section{Thomas Upton and Ulla Connor}

\begin{abstract}
Recently there has been a growing interest in and recognition of the value of specialized corpora, such as learner corpora [Granger, S. (1998). The computer learner corpus: a versatile new source of data for SLA research. In S. Granger, Learner English on computer (pp. 3-18). New York: Longman], in facilitating discourse analysis. Despite this trend, most corpus-based analyses have centered on the lexico-grammatical patterning of texts with less regard for functional and rhetorical, textlinguistic aspects [Flowerdew, L. (1998). Corpus linguistic techniques applied to textlinguistics. System, 26, 541-552]. The goals of this study were: (1) to demonstrate the efficacy of a multi-level analysis of a genre-specific learner corpus that included both a handtagged moves-analysis coupled with a computerized analysis of lexico-grammatical features of texts; and (2) to show how a pragmatic concept such as politeness can be operationalized to allow for computer generated counts of linguistic features related to that concept. In this study of politeness strategies used by Americans, Finns, and Belgians in a learner corpus of letters of application, we found that Americans as a group tended to be much more patterned, even formulaic, in their politeness strategies. The Belgians, on the other hand, showed more individuality in their letters with the Finns exhibiting both traits to lesser degrees. In this paper we argue for a textlinguistic approach that considers the special features of genre-specific corpora.
\end{abstract}

\section{Introduction}

Traditional genre analysis proposes "moves”, or functional components, as basic elements of a genre (Swales, 1990); indeed, it is argued that such moves can be taught to a novice writer of a particular genre ([Bhatia, 1993] and [Dudley-Evans, 1995]). Genres, furthermore, have cultural expectations - including disciplinary as well as national or ethnic - and crossing cultural boundaries ${ }^{1}$ requires re-learning at least part of the genre in light of its construction in the new culture. Negotiating cultural differences in genres would then be an expected part of writing for writers from one culture seeking to communicate with members of another culture.

\footnotetext{
${ }^{1}$ For the purposes of this analysis, we used a rather traditional view of culture that defines cultures as geographically and/or nationally distinct entities. We are aware of the changing definitions of culture in TESOL (Atkinson, 1999b) which recognize that cultures are not homogeneous and all-encompassing. However, as our purpose in this paper was to showcase a textlinguistic approach to discourse analysis and our sample of letters from each culture came from a narrow and specific cross-section of each culture, we feel that our use of a traditional view of culture can be justified.
} 
That genre expectation varies not only from genre to genre, but also from culture to culture has important ramifications on the growing field of corpus linguistics. The goal of corpus linguistics is to investigate the way people use language by analyzing large databases of real language examples (Biber, Conrad_\& Reppen, 1998). However, most current language corpora are eclectic collections of spoken and written text from a wide variety of native-language contexts. Although many of these corpora are quite large and much can be discerned about the general lexical and grammatical features of a language from them, they offer little insight into the moves or cultural expectations of individual genres that may make up the larger corpus.

Genre analysis argues first of all that attention to writing for specific purposes is crucial since particular tasks require additional strategies beyond general writing ability. Furthermore, knowing the situation, context, and stimulus is important since these may elicit different types of language based on cultural differences in interpreting purpose and genre by native and nonnative speakers of the language. Consequently, we need corpora that are limited to specific genres and that includes the writing requirements and the cultural contexts in which the texts are generated. This is particularly important when looking at the role culture plays in a genre. For example, the subtleties of accommodating one's writing for another culture should be apparent in tightly controlling for genre and purpose in a learner corpus.

In addition to calling for more specificity in applied learner corpus development with regard to situation, context, and stimulus, we will also show how a textlinguistic approach is useful in analyzing the corpus data. As Flowerdew (1998) points out, a great deal of the more applied, corpus-based analyses have focused on the lexico-grammatical patterning of text, producing collocations and lists of fixed phrases; much of this work has centered on the propositional level of texts, with less regard to functional and rhetorical aspects.

For pedagogical purposes these general patterns and lists are not always beneficial. For example, instead of producing simple lists of modals and hedges frequently used in English, it may be pedagogically more beneficial to show how these modals and hedges are used persuasively in, say, an application letter when politely indicating a desire for an interview - which is an application letter genre move.

To investigate these functional and rhetorical aspects of texts, Flowerdew calls for tagging not only lexicon and syntax, but also discourse features such as rhetorical moves. In Flowerdew's (1998, p. 159) words:

Another suggestion, which I believe would have wide pedagogical applications, is more exploitation of the tagging function of existing software on the market. As Leech (1991) remarks, most of the work on text annotation (tagging) has been done at the grammatical (word class) or syntactic (parsing) level. Very little has been done on the semantic or pragmatic discourse level to date. For example, text could be tagged manually to indicate the generic "move structures" such as background, scope, purpose in the introductory sections of a report. A goal of the present study was to apply a moves-based analysis to a genre-specific learner corpus. Moves were manually tagged on a corpus of job application letters. Cross-cultural similarities and differences were then investigated in the letters using a linguistic system of politeness strategies, adapted from Brown and Levinson (1987) and used by Maier (1992) in a 
previous study involving business letters composed by international students. Although our study yielded interesting information about cultural differences in the use of politeness strategies between cultural groups, our sample is too small and the analysis system too exploratory to add significantly to the discussion about cross-cultural theories of politeness. Instead, with the present study, we wanted to show the usefulness of a multi-level analysis of a computerized genre-specific learner corpus, namely an analysis that included hand-tagged moves and computer-run counts of linguistic features associated with aspects of politeness. The following sections of the paper will describe the data, the analyses - i.e. the moves analysis and the analysis of politeness strategies - and the findings related to the use of negative and positive politeness strategies.

\section{Methodology}

\subsection{The corpus}

Learner corpora represent an important new development in corpus linguistics. The most notable corpora include the International Corpus of Learner English (ICLE), a corpus of learner English of argumentative writing by students from many L1 backgrounds (Granger, 1998), and the Hong Kong University of Science and Technology (HKUST) Learner Corpus ${ }^{2}$ (Hyland \& Milton, 1997). The focus in these and many other learner corpora in collecting data is on argumentative essays, other timed writing exercises, or school assignments in general. Such learner corpora provide significant data on academic English for interlanguage contrasts, which are beneficial for research in L2 acquisition as well as L2 teaching.

However, recent research in genre analysis has focused more specifically on English for professional purposes using a variety of corpora. In fact, there is growing understanding that different types of writing skills and strategies are needed to perform different types of writing tasks. In order to control the investigation of the writing for a specific professional writing task, a very carefully controlled purpose - such as applying for a job - in a corpus is essential.

According to Swales (1990, p. 58), a genre is "a class of communicative events, the members of which share some set of communicative purposes". Further, he argues that genres have certain structural characteristics including a beginning, middle, and end. Letters of application clearly conform to this definition of a genre in that they have a well-defined purpose and readers have certain expectations of the content and format of such letters. As such, the prototypical forms of application letters can be studied in terms of content and structure as a genre.

Bhatia (1993) has the most complete discussion of letters of application as a genre. He found a six-part structure in his study of letters of application for academic positions at universities: establishing credentials, offering incentives, enclosing documents, using pressure tactics, soliciting response, and ending politely. Further, Bhatia noted that inadequate textualizations

2 A corpus of undergraduate assignments and "A" level Use of English exam essays from the Hong Kong Examination Authority. 
(written representations of intended meaning or communication goal) in the application letter could lead to failing to get short-listed for a job. To underscore the cultural implications of negotiating a genre across cultures, in a cross-cultural comparison of application letters, Bhatia pointed out that a significant difference between South-Asian application letters and Western letters was that the South-Asian letters failed to include a section selling one's qualifications to a prospective employer through a self-appraisal. In a Western context, this self-promotion in an application letter is considered essential, while the South-Asians consider it undesirable.

The data for the present study came from the Indianapolis Business Learner Corpus (IBLC), which is composed of job application letters and résumés of business communication students from the USA, Belgium, Finland, Germany, and Thailand. The corpus was initiated to help meet this need for situation-specific corpora. The general goals of the IBLC are to study language use, accommodation across cultures, and genre acquisition of native and non-native speaking students in an undergraduate business communication class. The data consist of a cross-cultural USFlemish-Finnish job application simulation. Participants in this simulation are undergraduate university students in courses which have parallel components, including: "1) instruction in international business writing; 2) a simulation, in which students exchange business documents internationally; and 3) case studies of business people who communicate internationally in writing” Connor,_Davis, De Rycker, Phillips, \& Verckens 1997, p. 65). ${ }^{3}$

The goal for this study was to try to locate in the corpus cross-cultural differences which may ultimately influence the efficacy of the letters of application written by the American and European participants. We examined data from three countries - Belgium, Finland, and the USA - from 1990, 1991, 1993, 1994, 1996, 1997, and 1998, with a total of 153 application letters analyzed. The total number of letters for each group of students is shown in Table 1 . The Belgian and Finnish participants were non-native speakers of English who had had at least six years of English instruction, though most participants had studied English longer than that. The Belgian and Finnish participants were, on average, younger and less experienced in business than the American participants. Most of the American students are returning to school after beginning their careers and are attending university part-time while working full-time.

\subsection{Moves analysis}

\footnotetext{
${ }^{3}$ The IBLC is compiled from the learner material generated during the simulation project. Each year, the USFlemish-Finnish writing project involves three simulated, but tailor-made and roughly identical job advertisements, describing a summer internship in an international business seminar to be held at the respective institutions. Job advertisements are written by the project instructors. Each group of students then writes cover letters and résumés for the foreign internship, and these letters and résumés are exchanged between the institutions. Students at each institution then go through the documents from their counterparts and, acting as simulated shortlisting committees, decide which candidates will get an invitation for a telephone interview. Students then indicate what the bases of their shortlisting decisions were. During all stages of this project, participants in each country discuss what they learned about the foreign students' textualizations and about their own textualizations in light of the foreign students' evaluations of their own letters.
} 
An analysis based on Swalesean genre moves was performed on initial data in this corpus of application letters from Belgium, Finland, and the USA, with genre-specific moves developed by Connor, Davis, and De Rycker (1995). The notion that prototypical forms of genres can be generated and studied is key for this study. A moves analysis is a useful methodology since moves are semantic/functional units of texts which can be identified first because of their communicative purposes and second because of linguistic boundaries typical of the moves. It must be noted, though, that the letters used to develop the moves for the genre represented in this corpus were generated by language learners and/or novice writers of letters of application. Further refinement of these moves will come once letters written by professional native speakers of English as well as professional and fluent non-native speakers of English from Belgium and Finland are incorporated into the corpus.

The study reported here employs the coding scheme for genre moves developed by Connor, Davis, and De Rycker (1995), with two minor modifications. These moves "describe the functions (or communicative intentions) which particular portions of the text realizes in relationship to the overall task of applying for... an overseas internship” (Connor, Davis, \& De Rycker, 1995, p. 463). Table 2 provides a description of the modified coding scheme. The two modifications from the original coding scheme include first of all an expansion of Move 4, "Indicate desire of an interview", to read as follows: "Indicate desire for an interview or a desire for further contact, or specify means of further communication/how to be contacted.” The second modification, not of major relevance to this paper, is the addition of a seventh move to the original six: "Reference attached résumé.” Examples from actual letters of each of the genre moves described later are given in Appendix A.

All of the letters were first electronically scanned and converted to computer text files, with scanning accuracy for each letter individually checked. Each of the letters was then coded for the rhetorical moves, described earlier, by two trained raters. On a check of inter-rater reliability, the two raters had an agreement rate of 92\% in identifying and categorizing the moves on 15 (10\%) randomly selected letters coded by both raters. The occurrence and boundaries of each move were then incorporated into the data. Quantitative analysis of linguistic features within moves was then performed on the letters by country, using the concordancing program Wordsmith, version 2.0 (Oxford University Press, 1997).

\subsection{Analysis of politeness strategies}

To show the value and efficacy of a multi-level analysis of a genre specific corpus, we conducted a corpus-based follow-up study on Maier's 1992 study of cross-cultural politeness strategies. In her small-scale study, Maier, using Brown and Levinson's (1987) model of politeness, compared 18 letters written by native English speakers and native Japanese speakers (with fairly low English proficiency) writing in English. Brown and Levinson describe an interactional model consisting of two dimensions of "face": one positive and one negative. Positive face reflects the need to be accepted and to 'belong'. Using positive politeness strategies, also called "solidarity" politeness by Scollon and Scollon (1981), the speaker seeks to reinforce the addressee's positive face by showing the addressee that the two of them are cooperators with common goals and expectations. 
Negative face reflects the desire for independence, to be able to act freely and unimpeded by others. Respect is indicated with negative politeness strategies by showing that the speaker does not intend to limit the addressee's freedom of action. Brown and Levinson (1987) argue that three variables influence the degree to which an act might threaten one's positive or negative face: (1) the social distance between the speaker and the addressee; (2) their "power" relative to each other; and (3) the "absolute ranking of impositions in the particular culture" (p. 74). If the speaker has less power than the addressee, for example, it is more likely the speaker will use negative politeness strategies to minimize the threat to the addressee's negative face.

Maier (1992) focused on the following of Brown and Levinson's (1987) negative politeness strategies: apologizing, going on record as incurring a debt, being pessimistic, being indirect, and giving deference. She also investigated the following positive politeness strategies: showing interest, offering a contribution or a benefit, and being optimistic. She found that in letters requesting an interview, the native speakers used more negative or deferential politeness strategies than the non-native speakers did. They mitigated their request using modals and used more indirect expressions. On the other hand, non-native speakers used more "potentially risky positive politeness strategies, and were more informal and direct than were native speakers" (Maier, p. 203).

In the present study, we sought to extend Maier's study to more proficient non-native speakers of English from European countries. To provide a more direct comparison to Maier's study, we examined the politeness strategies in the two parts ("moves") of our letters of application specifically requesting an interview (Move 4) and giving thanks for consideration (Move 5; see Table 2). It should be further noted that Maier (1992) conducted her analysis by analyzing individual sentences in her data by hand, looking line-by-line for phrases and sentences that matched the different types of politeness strategies. This is a reasonable approach when working with a small data set such as the 18 letters used in her study. However, since we were seeking to analyze 153 letters from three different cultural groups, a hand analysis as conducted by Maier would have been daunting. In order to facilitate the search for politeness strategies used by our letter writers, we sought to operationalize these strategies by noting their linguistic features so that searches for these strategies could be done by computer. How the different politeness strategies were linguistically identified follows later.

\section{Findings related to use of positive and negative politeness strategies}

As noted earlier, this study focused on the politeness strategies used within two specific moves: (1) Move 4 - indicating a desire for an interview or further contact, or specifying a means of further communication; and (2) Move 5 - expressing politeness (pleasantries) or appreciation at the end of the letter. While Move 4 might be considered by most professional writers as an important component of a letter of application, only 50\% of the Belgian letters (35/70) included this move, while $80 \%$ (45/57) of the American letters and 73\% (19/26) of the Finnish letters included a Move 4 (see Table 3). Details of Move 5 will be discussed later.

Unlike the subjects in Maier's (1992) study, and as would be expected from more proficient ESL students, there was not the same degree of ungrammatical expression, unorthodox form, or "impression of being somehow too casual, too desperate, too personal, or too detached" (p. 194). In fact, in many respects it was often difficult to differentiate between letters written by native 
and non-native speakers of English based on grammatical features. In contrast to the subjects in Maier's study who were all taking an ESL class, the subjects in our study had had more experiences with, and thus were more fluent in, English and were studying in English at their institutions. Sentences (1) and (2) below are two examples of sentences written by the non-native speakers in Maier's (p. 194) study:

(1) First I want to say, Sorry for not attend a job interview.

(2) Would you please give me one more chance for me...Please, please give me one more interview for me!

The three sets of sentences below are taken from the letters used in this study. The first sentence in each group was written by a native speaker of English; the second by a non-native speaker.

(3) When reviewing your list of candidates for this position, please consider me for an interview.

(4) I would very much appreciate having an interview with you during which I can prove my English communication skills.

(5) I would be happy to talk with you at your convenience about an interview.

(6) I am looking forward to hearing from you and meeting with you in an interview at your convenience.

(7) I am excited about this position and would like to discuss it further with you.

(8) I would very much appreciate being given an interview and if my application is successful I will do my utmost to forward the interests of the [position].

Nevertheless, as in study, there were differences in the ways the Belgians, Finns, and Americans constructed their letters (i.e. Moves 4 and 5) with regards to their use of politeness strategies.

\subsection{Negative politeness strategies}

Negative politeness strategies are intended to reinforce the speaker's respect for the addressee, showing that the speaker acknowledges the addressee's independence and freedom of action (Brown \& Levinson, 1987). These negative politeness strategies were manifested in a variety of ways and to varying degrees by the letter writers.

\subsubsection{Indirectness}

Indirectness is considered a negative politeness strategy, as the speaker is showing respect for and acknowledging distance from the addressee. Directness, on the other hand, can be rather risky for the speaker, as it threatens the independence of the addressee. After commands ("Give 
me...”), which none of the speakers used, some of the most direct linguistic structures are sentences that begin with "I”, “you”, or "my”. For example:

(9) I will be available in January for this position.

(10) I am available for an interview to discuss my qualifications and the job position at your convenience.

(11) My phone number is [phone number].

(12) You can reach me at my home address, or at [phone number].

However, sentences that begin with words other than "I", “you”, or "my” have more of a sense of indirectness. For example:

(13) Should additional information be required, you may reach me at my phone number [phone number].

(14) If you are interested in allowing me an opportunity to interview for the studentship, you can reach me at the enclosed address or telephone number.

(15) Please feel free to contact me at [phone number].

Table 4 shows how writers from different countries compare with their use of sentences beginning with words other than "I”, “you”, and "my”, as represented by sentences (13), (14), and (15) given earlier.

\subsubsection{Modals}

Modals that qualify statements have the effect of softening the idea being communicated. These types of modals fall under a category of modals called "social interactional" by Celce-Murcia and Larsen-Freeman (1999) because modal choice depends to a large extent on the speaker's perception of the social situation he or she is interacting in. The use of qualifying modals in Move 4 in these letters of application can be seen as a negative politeness strategy because these modals are intended to downplay the speaker's expectations while emphasizing the addressee's prerogative to control the situation, that is, the addressee's freedom of action. Modals that frequently serve to qualify statements include the following: would, could, may, might, shall ${ }^{4}$, and should ${ }^{5}$ (see Table 5).

\footnotetext{
4 "Shall", while generally a modal of obligation, can be used as a qualifying modal. The one example in this corpus of "shall" used as a qualifying model occurred in the following context: "If you feel that my qualifications meet with your requirements, I shall be pleased to come for an interview”.

${ }^{5}$ Each instance of "should" was individually examined to make sure that it served a qualifying purpose in the text, as opposed to indicating obligation. For example, in the sentence "Should you want to discuss my qualifications further..." the modal "should" is considered to serve a qualifying function.
} 
In these data, the Belgian writers use qualifying modals more than twice as often as the Finns (40 to $16 \%$ ) but about $20 \%$ less frequently than the Americans (40 to 51\%).

\subsubsection{Formulaic expressions as a negative politeness strategy}

Several formulaic expressions repeatedly occurred in these letters of application, both within and across cultures. This was expected since application letters are a genre and, as such, have not only a predictable structure but in many cases predictable formulaic expressions. While formulaic expressions are not in themselves necessarily a negative politeness strategy (see "look forward to..." later), the intent of many formulaic expressions is to couch personal desires and wishes behind genre-accepted formulas. The speaker is showing that he or she is playing by the rules of the game, so to speak. Within Moves 4 and 5, four formulaic expressions stood out: "I would/will appreciate...", "I am available for...", "at your convenience”, and "thank you for your (time and) consideration”.

As Table 6 shows, the Finns (79\%) used these formulaic expressions more than twice as often as the Belgians (31\%), and the Americans (91\%) used them almost three times more frequently than the Belgians.

\subsubsection{Expressing appreciation}

Brown and Levinson (1987, p. 210) classify the expression of appreciation as "going on record as incurring a debt". The statement of appreciation has been marked specifically as the genre Move 5 in our letters. As in Maier's (1992) study, native speakers of English relied much more heavily on this strategy of expressing gratitude as a means to soften their application letter. In terms of percentages, $40 \%$ of the American letters had expressions of gratitude, while $13 \%$ of the Belgian letters and as few as $4 \%$ of the Finnish letters contained the move (see Table 7).

Interestingly, as was shown before, while Move 4 tends to be more individualized, Move 5 is very formulaic. Nearly all of the expressions were some form of the phrase "Thank you for your consideration." The formulaic nature of Move 5 is in compliance with genre expectations ([Atkinson, 1999a] and [Bhatia, 1993]). A formulaic expression of gratitude (Move 5) seems to be expected in the American context, but does not seem to be expected in the Belgian and Finnish contexts. Thus, the presence or absence of Move 5 is probably more related to audience awareness and expectations of politeness markers than to the relative politeness/impoliteness of any of the groups. The expression of gratitude itself is not the issue here; rather, what is key is the difference in the writers' concept of what their audience expected - to be thanked or not to be thanked.

\subsection{Positive politeness strategies}

A speaker uses positive politeness strategies to emphasize the shared goals and common ground of the speaker and addressee. These strategies are most effective when both the speaker and the addressee see themselves as equals or as colleagues. The risk, then, in using positive politeness strategies is that the addressee may not view the speaker as belonging to the addressee's group and may take offense. Maier (1992) found that non-native speakers tended to use positive 
politeness strategies much more frequently than native speakers did and, as a result, did not write as effective letters. Within Move 4 of the letters used in this study, positive politeness strategies were most evident in the speakers' directness and sense of optimism.

\subsubsection{Directness}

Two common structures stood out as fairly direct, and thus more threatening of the independence of the addressee. These were sentences that started with the phrase "You can..." or the phrase "Please [+ action verb]...", both of which give the impression of a command, although polite. Table 8 compares the occurrences of these structures by country for both Moves 4 and 5 .

\subsubsection{Be optimistic}

Optimism is considered a positive politeness strategy because it connects with the addressee's desire to have his or her needs met. It also demonstrates that the speaker is trying to minimize the distance between speaker and addressee by showing that they have common goals. Optimism was most commonly expressed through the phrase "look forward to", but also with the word "hope". Table 9 shows these expressions of optimism as they were expressed by country within Move 4. There were no instances of either phrase in Move 5 for any of the three countries represented in the corpus.

\section{Summary of findings related to the use of politeness strategies}

The results showed that none of the three groups used either positive or negative politeness strategies exclusively, or even more frequently than another group. We did find differences, however, in the use of specific politeness strategies among the groups. In Maier's (1992) study, she found differences in the comparative use of positive and negative politeness strategies between native and non-native speakers of English, specifically, that native speakers use negative politeness more, while non-native speakers tended toward positive politeness. There does not appear to be such a clear-cut distinction in the data in our corpus. What stands out more is the type of negative and positive strategies used.

The Americans as a group tended to be much more patterned, even formulaic, in their politeness strategies - whether positive or negative; the Belgians, at the other extreme, incorporated their positive and negative politeness strategies into more varied and individualized letters. The Americans relied heavily on more direct, independent clause-initiated sentences that began with "I, You, or My" (76\% of sentences vs. 57\% of Belgian sentences). They more frequently (91 vs. $31 \%$ for Belgians) incorporated genre specific formulaic expressions into their letters (e.g. "thank you for your consideration"). The Americans, also, far more frequently used the formulaic rhetorical function of Move 5 - expressing politeness and/or appreciation (40 vs. 13\% of Belgians).

The Belgians, on the other hand, showed more individuality in their letters, incorporating a wider variety of sentence opening structures than the Americans, using more qualifying modals not tied to formulaic expressions, and much less frequently employed formulaic expressions and structures in general. 
The Finns fell between the Belgians and the Americans on the continuum, showing more affinity to the formula-oriented style of the American writers but also incorporating some of the more individualistic style of the Belgians when seeking to develop an appropriately polite letter of application.

Level of language proficiency as well as type of instruction must certainly be taken into consideration, but the reason for the differences in the use of politeness strategies across countries may be partly due to differences in audience expectations and writer concepts of how politeness is expressed. What must be considered is to whom the letter of application is being written. What language is appropriately polite will vary depending on whether that addressee is American, Belgian, or Finnish.

For the purposes of this study, we found the operationalization of politeness strategies using explicit linguistic features to be workable, allowing us to quantify the genre analysis and more easily make comparisons among the groups. We underscore, however, that the analyses are suggestive and should be subjected to further verification before firm conclusions about crosscultural differences are made.

\section{Conclusion}

Our paper has been exploratory in nature in a number of ways. First, we wanted to demonstrate the efficacy of a multi-level analysis of a genre-specific learner corpus that included both a handtagged moves-analysis coupled with a computerized analysis of lexico-grammatical features of texts. This is in response to Flowerdew's (1998) call, noted earlier, for more research using computer tagging to study text at the semantic or pragmatic discourse level.

In this paper, we have also shown how a pragmatic concept such as politeness can be operationalized to allow for counts of linguistic features related to politeness. This is in keeping with Biber, Conrad, and Reppen (1998, p. 5) contention that "corpus-based analyses must go beyond simple counts of linguistic features. That is, it is essential to include qualitative, functional interpretations of quantitative patterns." We believe that a textlinguistic approach to the computerized analyses of corpora, as advocated by Biber, Conrad, and Reppen and Flowerdew (1998), is not only desirable but can be quite fruitful, particularly with specialized, genre-specific corpora.

Finally, as illustrated by the corpus used in this study, we believe that specialized, genre-specific corpora will continue to grow in importance not only for instructional purposes in academic settings but also in professional and business contexts. That language use can dramatically differ from context to context or genre to genre has been clearly shown by Biber, Johansson, Leech, Conrad, and Finegan (1999). Consequently, specialized corpora allow for a more thorough understanding of how language is used in particular contexts or in particular genres. 
[This space left blank intentionally]

\section{List of Tables}

Table 1

Application letters by country

\begin{tabular}{ll} 
Country & No. of letters \\
Belgium & 70 \\
Finland & 26 \\
USA & 57 \\
\hline
\end{tabular}

Table 2 
Learner letter of application genre moves: a coding scheme

1. Identify the source of information. (Explain how and where you learned of the position.)

2. Apply for the position. (State desire for consideration.)

3. Provide argument, including supporting information, for the job application.

a. Implicit argument based on neutral evidence or information about background and experience.

b. Argument based on what would be good for the hiring company. ("My intercultural training will be an asset to your international negotiations team. ${ }^{D}$ )

c. Argument based on what would be good for the applicant. ("This job will give me the opportunity to test my intercultural training.")

4. Indicate desire for an interview or a desire for further contact, or specify means of further communication/how to be contacted.

5. Express politeness (pleasantries) or appreciation at the end of the letter.

6. Offer to provide more information.

7. Reference attached résumé.

\section{Table 3}

Occurrence of Move 4 in letters of application

\begin{tabular}{ll}
\hline & Percent of letters with Move 4 \\
Belgium & $50(35 / 70)$ \\
Finland & $73(19 / 26)$ \\
USA & $80(45 / 57)$ \\
\hline
\end{tabular}

Table 4

Sentences and move initial clauses starting with words other than "I, you, and my" in Move 4

\begin{tabular}{llll}
\hline & No. of occurrences & Total no. of Move 4 sentences & Mean no. of "indirect" sentences (\%) \\
Belgium & 19 & 44 & 43 \\
Finland & 6 & 28 & 21 \\
USA & 16 & 68 & 24 \\
\hline
\end{tabular}

\section{Table 5}

Use of qualifying modals in Move 4 


\begin{tabular}{llll}
\hline & Belgium & Finland & USA \\
Could & 1 & 1 & 0 \\
May & 0 & 0 & 8 \\
Shall & 1 & 0 & 0 \\
Might & 0 & 0 & 0 \\
Should & 2 & 0 & 3 \\
Would & 10 & 2 & 12 \\
No. qualifying modals & 14 & 3 & 23 \\
No. of letters with Move 4 & 35 & 19 & 45 \\
& & & \\
Rate modal use (\%) & 40 & 16 & 51 \\
\hline
\end{tabular}

[This space left blank intentionally.]

Table 6

Use of formulaic expressions in Moves 4 and 5 


\begin{tabular}{llll}
\hline & Belgium & Finland & USA \\
Would/will appreciate & 4 & 0 & 2 \\
Am available for & 1 & 8 & 3 \\
At your convenience & 0 & 6 & 16 \\
You may reach me... & 0 & 0 & 5 \\
Thank you for...consideration & 6 & 1 & 15 \\
No. formulaic expressions & 11 & 15 & 41 \\
No. of letters with Move 4 and 5 & 35 & 19 & 45 \\
Rate of formulaic expressions in Moves 4 and 5 (\%) & 31 & 79 & 91 \\
\hline
\end{tabular}

Table 7

Use of Move 5, “Expressing appreciation”

\begin{tabular}{llll}
\hline & No. of Move 5 occurrences & No. of letters & Rate of Move 5 use (\%) \\
Belgium & 9 & 70 & 13 \\
Finland & 1 & 26 & 4 \\
USA & 23 & 57 & 40 \\
\hline
\end{tabular}

[This space left blank intentionally.]

\section{Acknowledgements}


We would like to thank Bengt Altenberg, Ken Davis, and Tuija Virtanen, as well as the anonymous reviewers, for their extensive comments and feedback on earlier drafts of this paper. Data collection and analysis for this study were supported by the Indiana Center for Intercultural Communication, Indiana University Purdue University Indianapolis

\section{References}

1. Atkinson, D., Scientific discourse in sociohistorical context: the philosophical transactions of the Royal Society of London, 1675-1975, Erlbaum, Mahwah, NJ (1999).

2. Atkinson, D., TESOL and culture, TESOL Quarterly 33 (4) (1999), pp. 625-654.

3. Bhatia, V., Analyzing genre: language use in professional settings, Longman, New York (1993).

4. Biber, D., et al, Corpus linguistics: investigating language structure and use, Cambridge University Press, Cambridge, UK (1998).

5. Biber, D., et al, Longman grammar of spoken and written English, Pearson Education Limited, London (1999).

6. Brown, $\mathrm{P}$, et al, Politeness: some universals in language usage, Cambridge University Press, Cambridge (1987).

7. Celce-Murcia, M., et al, The grammar book: an ESL/EFL teacher's course (2nd ed.), Heinle \& Heinle, Boston, MA (1999).

8. Connor, U., et al, An international course in international business writing: Belgium, Finland, the United States, Business Communication Quarterly 60 (4) (1997), pp. 63-74.

9. Connor, U., et al, Correctness and clarity in applying for overseas jobs: a cross-cultural analysis of U.S. and Flemish applications, Text 15 (4) (1995), pp. 457-476.

10. Dudley-Evans, T., Genre models for the teaching of academic writing to second language speakers: advantages and disadvantages, The Journal of TESOL-France 1 (1995), pp. 181-192.

11. Flowerdew, L., Corpus linguistic techniques applied to textlinguistics, System 26 (1998), pp. 541-552.

12. Granger,S., The computer learner corpus: a versatile new source of data for SLA research. In: S Granger, Editor, Learner English on computer, Longman, New York (1998), pp. 3-18.

13. Hyland, K., et al, Qualification and certainty in L1 and L2 students' writing, Journal of Second Language Writing 6 (2) (1997), pp. 183-205.

14. Leech, G., The state of the art in corpus linguistics. In: K Aijmer and B Altenberg, Editors, English corpus linguistics: studies in honour of Jan Svartvik, Longman, London (1991), pp. 8-29.

15. Maier, P., Politeness strategies in business letters by native and non-native English speakers, English for Specific Purposes 11 (1992), pp. 189-205.

16. Scollon, R., et al, Narrative, literacy, and face in interethnic communication, Ablex, Norwood, NJ (1981). 
17. Swales, J., Genre analysis: English in academic and research settings, Cambridge University Press, New York (1990).

\section{Appendix A. Move samples}

\section{Identify the source of information. (Explain how and where you learned of the position.)}

"I was delighted to hear from Professor Ken Davis of your plans to create a team to investigate global business issues."

"I recently received word from Blockbuster Recruiting about a management position available at your company.”

“After reading your advertisement ..." [only this part of the sentence is move 1].

\section{Apply for the position. (State desire for consideration.)}

"I am very interested in the vacancy of an intern."

"I am very interested in a temporary job working as a European business student intern in the U.S.A.”

“This is why I am applying for the 13 June 1994 student internship.”

"I hope that you will consider me for this position."

\section{Provide argument, including supporting information, for the job application.}

a. Implicit argument based on neutral evidence or information about background and experience.

In providing supporting information or arguments, the writers sometimes simply listed their background experience. These descriptions seem to be putting information from the résumé into prose:

"I will be completing my degree of Business-Accounting in December of 1993. My current employment requires collecting, processing, and interpreting data every day. I summarize this data into a report which is sent to top executives of corporations for them to make decisions. I am very interested in the globalized economy, especially the US and EC business environment. My oral and written English are very fluent and my communication skills are excellent.” 
"I received my Associates Degree in General Studies in May 1993. Previously I have received a degree in Office Management from Indiana Business College and I have obtained the Certified Professional Secretary (CPS) certification...”

b. Argument based on what would be good for the hiring company. ("My intercultural training will be an asset to your international negotiations team.")

In 3b, the writers argue explicitly that their experience or education will benefit the company that hires them. This includes the entire argument structure.

"I feel I can offer my business experience which I have gained working as an Accountant."

"I have a strong desire to work in some way with an international system, and although I am sure that positions with your institution are very competitive, I am sure I can be of benefit.”

"I also feel that my communication skills and employment experience would be beneficial to your research team.”

"I believe that my interest in the subject, as well as my background and work experience, will enable me to contribute to your project."

c. Argument based on what would be good for the applicant. ("This job will give me the opportunity to test my intercultural training.")

Sometimes the writers directly stated how the experience would benefit them. The evidence in this argument is an aspect of the employment position which would be beneficial to the applicant, rather than discussing the applicants' background. This includes the entire argument structure.

"This Studentship will offer me good experience in International business.”

"The opportunity to study abroad the globalised business environment would help me gain the knowledge and experience to grow in the changing business world of today.”

"This would be a perfect opportunity to have foreign business experience."

"This is a unique opportunity to create an impartial view of the American way of life in general and the working of a foreign university in particular."

4. Indicate desire for an interview or a desire for further contact, or specify means of further communication/how to be contacted.

"I hope I got you interested so that I will be selected for an interview."

"I'm always prepared to participate in an interview." 
"Let us get together to discuss the position and the possible opportunity to work with you in Belgium.”

"I will look forward to your call.”

"My telephone number at work is $<\mathrm{PH}>$, and at home is $<\mathrm{PH}>$."

"Please feel free to contact me at $<\mathrm{PH}>$."

"I can be reached at the above address."

\section{Express politeness (pleasantries) or appreciation at the end of the letter.}

“Thank you in advance for your consideration.”

"I should be very grateful for a favorable consideration of my application..."

"If the position referred to is still vacant I would be grateful for the opportunity of an interview with one of your responsible colleagues." [underlined section only; the second half is move 4 ("request for interview")]

“Thank you for your time in reviewing this material.”

\section{Offer to provide more information.}

"I can be reached at the above address should you need any further information." [underlined section only]

"I'm prepared to send you more information."

“I will be happy to provide you with any additional information that you may need.”

\section{Reference attached résumé.}

“I have enclosed my résumé...”

“A résumé is enclosed."

“Enclosed is a copy of my résumé (CV) which will provide additional data.”

"As you will see from my enclosed curriculum vitae I worked parallel to my studies for Lufthansa as Senior Flight Attendant.” [underlined section only; the rest is 3a.] 